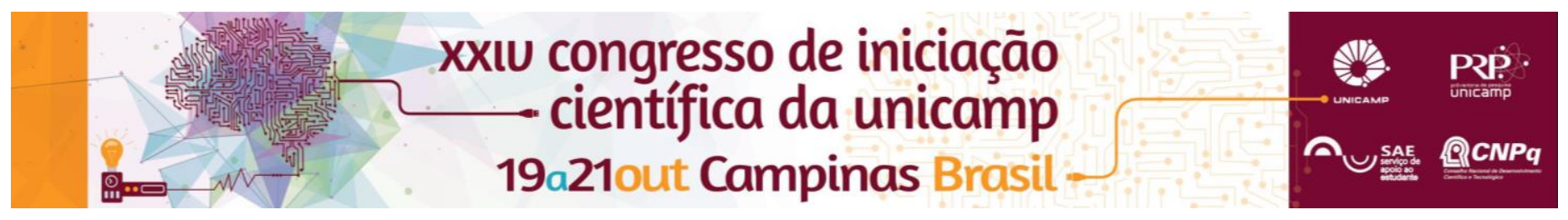

\title{
UTILIZAÇÃO DE COBALTO COMO METAL INDUTOR PARA ELETRODEPOSIÇÃO DE TUNGSTÊNIO
}

\author{
Rodolfo José Amancio*, Ambrósio Florêncio de Almeida Neto
}

\begin{abstract}
Resumo
Neste trabalho o cobalto foi utilizado como metal indutor para a eletrodeposição de tungstênio. As liga formada de cobalto e tungstênio foram obtidas em diferentes condições, seguindo um planejamento $2^{2}$ em que avaliou-se os efeitos das concentrações de cobalto e tungstênio, no banho eletrolítico, sobre a morfologia, cristalinidade, composição química e pureza. Os resultados experimentais revelaram que a máxima eficiência de deposição $(69,33 \%)$ foi obtida para a condição de máximas concentrações dos metais no banho. A eletrodeposição por períodos de tempo maiores que 60 minutos permitia a obtenção de quantidades maiores de liga, por outro lado, a massa elevada desse material não apresentava aderência, sendo o tempo ótimo de eletrodeposição de uma hora.
\end{abstract}

Palavras-chave: Corrosão, eletrodeposição, revestimento.

\section{Introdução}

Tungstênio é um metal que apresenta, em seu estado puro, propriedades propícias para seu emprego como revestimento metálico. Por outro lado, sua eletrodeposição em estado puro não vem obtendo resultados satisfatórios. Pode-se, entretanto, elevar a eficiência dessa deposição com o emprego de um metal indutor, que favorece a eletrodeposição do tungstênio'. Esse processo é chamado de eletrodeposição induzida, e esse trabalho avaliou o emprego de cobalto como metal indutor, analisando as diferentes composições do banho para a formação da liga de Co-W.

\section{Resultados e Discussão}

Os ensaios de eletrodeposição foram realizados com rotação catódica de $15 \mathrm{rpm}$, densidade de corrente de 50 $\mathrm{mA} / \mathrm{cm}^{2}$ e temperatura ambiente. $\mathrm{O} \mathrm{pH}$ foi sempre mantido na faixa de 7 , tal valor foi determinado por meio de simulações computacionais, utilizando os softwares Hydra e Medusa. Para avaliar o efeito das concentrações de metais do banho eletrolítico, sobre a eficiência de deposição e principais características da liga de Co-W, foi realizado o planejamento experimental $2^{2}$ da Tabela 1 .

Tabela 1. Planejamento experimental.

\begin{tabular}{|c|c|c|c|c|}
\hline \multicolumn{2}{|c|}{ Níveis } & -1 & 0 & +1 \\
\hline \multirow{2}{*}{ Variáveis } & $\mathrm{C}_{\mathrm{Co}}(\mathrm{mol} / \mathrm{L})$ & 0,1 & 0,2 & 0,3 \\
\cline { 2 - 5 } & $\mathrm{C}_{\mathrm{w}}(\mathrm{mol} / \mathrm{L})$ & 0,1 & 0,2 & 0,3 \\
\hline
\end{tabular}

A partir da Espectroscopia por Energia Dispersiva de Raios X (EDX) determinou-se a composição das ligas metálicas e a eficiência de eletrodeposição foi calculada. Essa última apresentou altos valores nas condições experimentais estudadas. A Figura 1 mostra 0 comportamento da eficiência de eletrodeposição em função da composição do banho. É possível verificar que a maior eficiência de deposição foi obtida nas maiores concentrações de Co e W. Observou-se também que a liga de Co-W apresentou boa aderência com uma hora de eletrodeposição. As análises de Difração de Raios $X$ (DRX) e Espetroscopia de Infravermelho com Transformada de Fourier (FTIR) apresentaram resultados variados, que foram resumidos na Tabela 2.
Tabela 2. Resultados de DRX e FTIR.

\begin{tabular}{|c|c|c|c|}
\hline Nível & Amostra & DRX & FTIR \\
\hline$(-1 ;-1)$ & 1 & Cristalina & Sem impureza \\
\hline$(-1 ;+1)$ & 2 & Amorfa & Com impureza \\
\hline$(+1 ;-1)$ & 3 & Cristalina & Com impureza \\
\hline$(+1 ;+1)$ & 4 & Cristalina & Sem impureza \\
\hline$(0: 0)$ & 5 & Amorfa & Com impureza \\
\hline
\end{tabular}

Figura 1. Eficiência de eletrodeposição

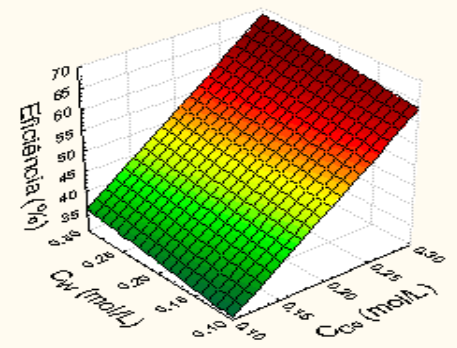

Por fim, a análise via Microscopia Eletrônica de varredura (MEV) revelou a presença de microfissuras - que podem fragilizar o material - em todas as amostras, mas com maior incidência na amostra 2, e moderada nas demais. Uma liga amorfa, sem impurezas e sem microfissuras constituirá um excelente revestimento. Assim, esse estudo pode concluir que a liga de Co-W apresentou algumas dessas características, podendo ser utilizadas para proteção contra corrosão.

\section{Conclusões}

A eletrodeposição de Co-W apresentou eficiência de deposição entre $31,50 \%$ e $69,33 \%$. As análises físicoquímicas da liga revelaram características favoráveis ao seu emprego na proteção contra corrosão. Verificou-se que tempos elevados de deposição fragilizavam a liga, determinando uma hora de ensaio, como sendo um tempo adequado de eletrodeposição.

\section{Ao $\mathrm{PIBIC/CNPq}$.}

\section{Agradecimentos}

${ }^{1}$ A. Brenner; Electrodeposition of Alloys, Academic Press, New York, 1963, $\operatorname{vol} .2$ 